\title{
Precious metal carborane polymer nanoparticles: characterisation of micellar formulations and anticancer activity
}

\author{
Nicolas P. E. Barry, ${ }^{\text {aa }}$ Anaïs Pitto-Barry, ${ }^{a}$ Isolda Romero-Canelón, ${ }^{a}$ \\ Johanna Tran, ${ }^{a}$ Joan J. Soldevila-Barreda, ${ }^{a}$ Ian Hands-Portman, ${ }^{b}$ \\ Corinne J. Smith, ${ }^{b}$ Nigel Kirby, ${ }^{c}$ Andrew P. Dove, ${ }^{a}$ Rachel K. O'Reilly ${ }^{a}$ \\ and Peter J. Sadler*a
}

Received 7th May 2014, Accepted 16th June 2014

DOI: $10.1039 / c 4 f d 00098 f$

We report the encapsulation of highly hydrophobic 16-electron organometallic ruthenium and osmium carborane complexes [Ru/Os(p-cymene)(1,2-dicarba-closododecarborane-1,2-dithiolate)] (1 and 2) in Pluronic $®$ triblock copolymer P123 coreshell micelles. The spherical nanoparticles RuMs and OsMs, dispersed in water, were characterized by dynamic light scattering (DLS), cryogenic transmission electron microscopy (cryo-TEM), and synchrotron small-angle X-ray scattering (SAXS; diameter ca. 15 and $19 \mathrm{~nm}$, respectively). Complexes 1 and 2 were highly active towards A2780 human ovarian cancer cells ( $\mathrm{IC}_{50} 0.17$ and $2.50 \mu \mathrm{M}$, respectively) and the encapsulated complexes, as RuMs and OsMs nanoparticles, were less potent $\left(\mathrm{IC}_{50} 6.69 \mu \mathrm{M}\right.$ and 117.5 $\mu \mathrm{M}$, respectively), but more selective towards cancer cells compared to normal cells.

\section{Introduction}

Dicarba-closo-dodecarboranes are a class of boron-rich compounds with globular structures and diameters of $c a .1 \mathrm{~nm}$ (diameter of a rotating phenyl) that possess unusual properties, including high symmetry and remarkable stability. ${ }^{1}$ These characteristics have given rise to numerous applications, and carboranes have been used as building blocks in various systems, such as dendrimers, ${ }^{2}$ polymers ${ }^{3}$ and nanoparticles. ${ }^{4,5}$ They also have been extensively studied as potential boron neutron capture (BNCT) therapeutic agents, ${ }^{6,7}$ and as bioisosters of phenyl groups and pharmacophores for targeted drug development. ${ }^{8}$ Nevertheless, selective and effective delivery of boron agents is still a key issue that hinders their further clinical development. ${ }^{9}$ On the other hand, half-sandwich complexes of ruthenium

${ }^{a}$ Department of Chemistry, University of Warwick, Gibbet Hill Road, Coventry CV4 7AL, UK. E-mail: N.Barry@ warwick.ac.uk; P.J.Sadler@warwick.ac.uk

${ }^{b}$ School of Life Sciences, University of Warwick, Gibbet Hill Road, Coventry CV4 7AL, UK

${ }^{c}$ Australian Synchrotron, 800 Blackburn Road, Clayton, Victoria 3168, Australia 
and osmium are a versatile class of organometallic compounds. Their biological properties have raised considerable expectations for their use in the treatment of cancer since the early 2000s, and they are considered a promising alternative to platinum-based chemotherapeutics. ${ }^{\mathbf{1 0 , 1 1}}$ We have recently discussed how the combination of arene ruthenium(II)/osmium(II) complexes and carboranes has unexplored potential in medicine. ${ }^{12}$ Furthermore, such complexes exhibit unusual chemistry: coordination of the bulky, electron-deficient carborane ligand 1,2-dicarba-closo-dodecarborane-1,2-dithiolato to an arene-Ru or Os metal centre leads to the isolation of rare stable 16-electron complexes, such as $[\mathrm{Ru} / \mathrm{Os}(p-$ cymene)(1,2-dicarba-closo-dodecarborane-1,2-dithiolate)] (1 and 2). However, these complexes are highly hydrophobic, and their biological applications are impaired by the lack of solubility in water. We have recently discussed how nanotechnology may help to overcome such challenges in medicinal inorganic chemistry. ${ }^{13}$ Here, we report the encapsulation of these hydrophobic complexes in water-soluble polymer micelles.

The class of ABA triblock copolymers, where $\mathrm{A}=$ hydrophilic block poly(ethylene oxide) (PEO) and B = hydrophobic block poly(propylene oxide) (PPO), are commercially available as Pluronic ${ }^{\circledR}$ (non-proprietary name "poloxamers") and offer a pool of more than 50 amphiphilic, ${ }^{14}$ water-soluble and polymorphic materials. The physical and chemical properties of Pluronic $₫$ copolymers can be finely tuned by modifying the molar mass ratio between the PEO and PPO blocks (from $1: 9$ to $8: 2$ ), which directly modifies their in vivo properties and interactions with cells and cell membranes, thus providing high potential for the design of innovative nanomedicines and new biomaterials..$^{15}$ To exploit the chemistry of carborane-containing arene ruthenium complexes in aqueous solution, and to take advantage of their unique properties, we have encapsulated the 16-electron complexes 1 and 2 in Pluronic ${ }^{\circledR}$ triblock copolymer P123 micelles (Fig. 1). The resulting polymeric micelles RuMs and OsMs, dispersed in water, have been characterized by UV-visible spectroscopy, DLS, cryo-TEM, and SAXS studies.

Complexes 1 and $\mathbf{2}$ and micelles RuMs and OsMs were tested against the A2780 human ovarian cancer cell line. The ruthenium-based complex and micelles were also tested against MRC5 fibroblasts, as an example of non-cancerous, but fast dividing, cells to determine their selectivity and potential therapeutic window. Such a nanotechnology-based strategy not only allows the utilisation of precious

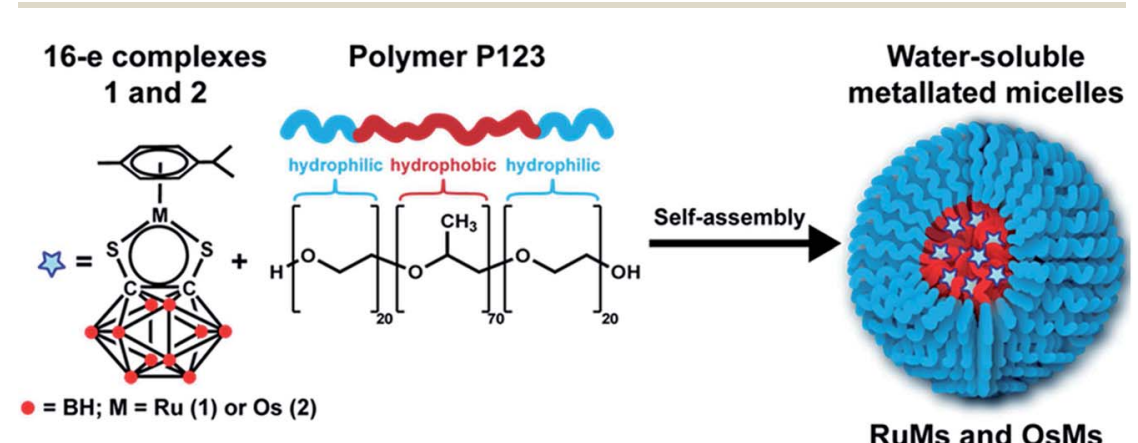

Fig. 1 Self-assembly formation of RuMs and OsMs (the red dots in 1 and 2 are boronhydrogen vertices). 
metal complexes containing carborane ligands in aqueous solution, but also offers the possibility of formulating and delivering a large number of these complexes ( $c a .60$ per particle) to cancer cells, thus generating a high intracellular boron concentration ( $c a .600$ per particle). There is currently much interest in the therapeutic use of boron-based pharmaceuticals, owing to their chemico-biological properties, to expand potential medical applications in prevention, diagnosis and therapy. ${ }^{\mathbf{1 6}}$

\section{Characterisation of the micellar formulations RuMs and OsMs}

The organometallic half-sandwich $\mathrm{Ru}^{\mathrm{II}}$ and $\mathrm{Os}^{\mathrm{II}}$ arene complexes $[\mathrm{Ru} / \mathrm{Os}(p$ cymene)(1,2-dicarba-closo-dodecarborane-1,2-dithiolate)] (1/2) were synthesized as previously reported. ${ }^{17}$ These complexes have a pseudo-octahedral structure, with a $\pi$-bonded arene occupying 3 coordination sites, a S-bound chelated dithiolato dicarba-closo-dodecarborane ligand, and a vacant $6^{\text {th }}$ site (Fig. 1). They are 16-electron complexes and therefore electron-deficient at the metal. ${ }^{18}$ Complexes 1 and $\mathbf{2}$ are highly hydrophobic and insoluble in water. ${ }^{8}$ To achieve dispersion in water, ${ }^{13}$ we encapsulated 1 and 2 in the water-soluble amphiphilic triblock copolymer P123 (poly(ethylene glycol)-block-poly(propylene glycol)-blockpoly(ethylene glycol)) (PEO-PPO-PEO), by mixing a tetrahydrofuran (THF) solution of 1 or 2 with an aqueous solution of polymer P123 $\left(\mathrm{THF}-\mathrm{H}_{2} \mathrm{O}: 1 / 10 \mathrm{v} / \mathrm{v}\right.$; [complex] $=5 \mathrm{mg} \mathrm{mL}^{-1}$ ), at ambient temperature for $4 \mathrm{~h}$ (Fig. 1). The encapsulation of the metal complexes in P123 micelles (P123Ms) was accompanied by a dramatic colour change from transparent to blue and purple for RuMs and OsMs, respectively, indicative of the presence of the 16-electron complexes $\mathbf{1}$ and $\mathbf{2}$ in the micelles. We have recently reported the full characterisation of OsMs micelles, ${ }^{19}$ and now present the characterisation of micellar formulation RuMs, in comparison with previous data obtained on OsMs micelles.

Dynamic light scattering (DLS) experiments (Fig. 2) unambiguously demonstrated that polymer P123 and complex 1 and 2 self-assemble in aqueous solution. Encapsulation decreased the micellar size (hydrodynamic diameter) of P123 from

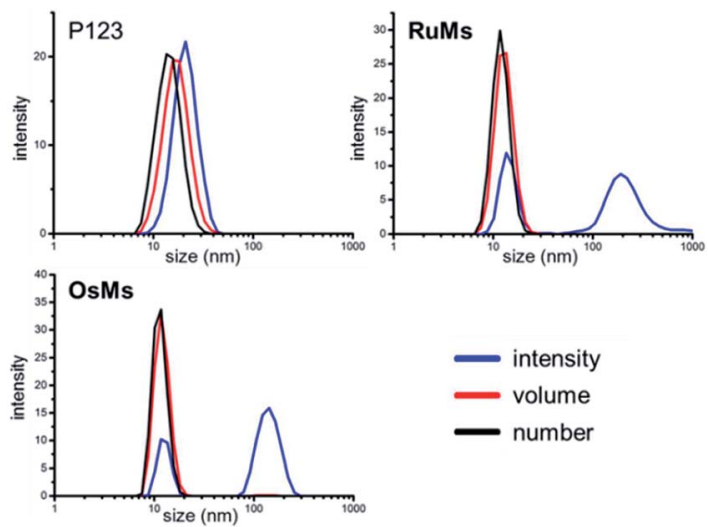

Fig. 2 DLS spectra of P123Ms, RuMs, and OsMs (1 mg mL $\left.\mathrm{mL}^{-1}, \mathrm{H}_{2} \mathrm{O}\right)$. 
$19.6 \pm 1.8 \mathrm{~nm}$ to $11.9 \pm 4.1 \mathrm{~nm}$ for RuMs and $11.5 \pm 2.3 \mathrm{~nm}$ for OsMs with dispersities $(D)$ of 0.04 and 0.03 , respectively. Although micellar size usually increases after encapsulation of organic molecules, incorporation of hydrophobic molecules can result in expulsion of water from micelles, causing a contraction. ${ }^{20}$ The hydrophobicity of $\mathbf{1}$ and $\mathbf{2}$ probably results in a stronger folding of the PPO chains around the complexes through hydrophobic interactions, with concomitant expulsion of water from the core. A small-in-number $(<0.01 \%$ in number $)$ second population of RuMs and OsMs particles is found at $D_{\mathrm{h}} \sim 220 \mathrm{~nm}$, which exhibits a strong intensity in DLS and is due to aggregation of some particles.

Cryo-TEM analysis without staining was performed on Quantifoil@ carboncoated grids, in order to observe the morphology of the nanoparticles in solution. The high contrast provided by the presence of the heavy ruthenium and osmium centres allowed facile imaging without staining (Fig. 3). From these analyses, it was clear that spherical micellar morphologies are formed when polymer P123 encapsulates complexes 1 or 2 . The observed diameters of these nano-spheres are $10.45 \pm 3.43 \mathrm{~nm}$ for RuMs and $7.85 \pm 1.97 \mathrm{~nm}$ for OsMs with very low dispersities $(<1.12)$. These data are in accordance with the hydrodynamic diameters determined by DLS, within experimental error.

To gain further insight into their structures in aqueous solution, and to confirm cryo-TEM and DLS results, RuMs, OsMs and P123Ms were analyzed by SAXS (Fig. 4). The experimental profiles were fitted using IgorPro software ${ }^{21}$ to three model functions for spherical micelles: SphereForm, ${ }^{22}$ CoreShellSphere,${ }^{22}$ and PolyCoreShellRatio ${ }^{23}$ (PCR). The PCR model fitted excellently for all micelles with very low dispersity parameters ( 0.124 for RuMs, 0.161 for OsMs and 0.146 for P123Ms, 0 being an ideal mono-disperse system, Table 1). These analyses demonstrated that RuMs and OsMs self-assembly leads to core-shell micelles with a core diameter of $9.88 \pm 0.25 \mathrm{~nm}$ and $9.06 \pm 0.12 \mathrm{~nm}$, and a shell diameter of $9.09 \pm 0.29 \mathrm{~nm}$ and $6.50 \pm 0.15 \mathrm{~nm}$, respectively (Table 1). The diameters of
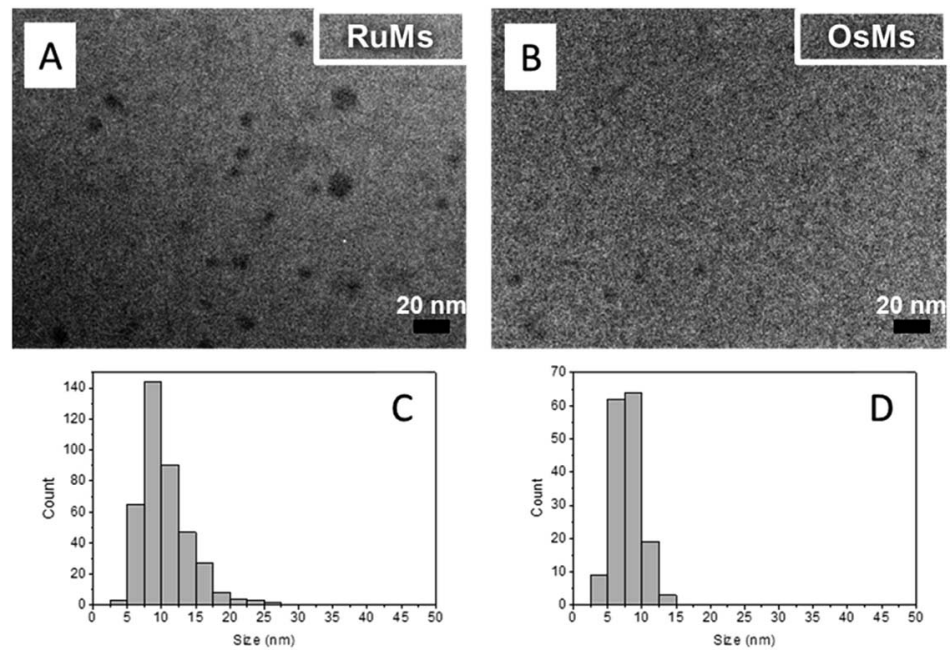

Fig. 3 Cryo-TEM of the self-assembled block copolymer micelles containing encapsulated ruthenium and osmium carborane complexes. (A) and (B) are images and (C) and (D) are particle counting/histogram analyses for RuMs and OsMs, respectively. 


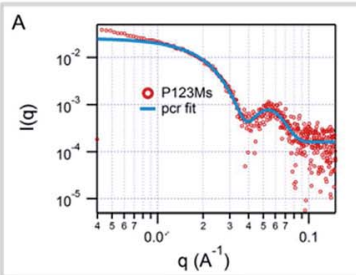

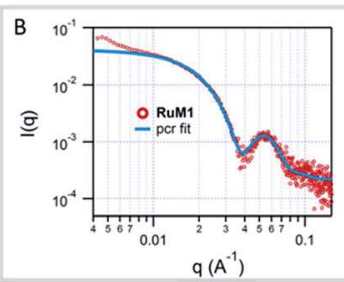

Fig. 4 Small-angle $X$-ray scattering (SAXS) experimental profiles and fitting with the PolyCoreShellRatio model of micelles (A) P123Ms, (B) RuMs, (C) OsMs: $1 \mathrm{mg} \mathrm{mL}^{-1}$ aqueous solutions.

Table 1 Physical characteristics of RuMs and P123Ms micelles determined by DLS, cryoTEM and SAXS at $1 \mathrm{mg} \mathrm{mL}^{-1}$

\begin{tabular}{|c|c|c|c|}
\hline \multirow[b]{2}{*}{ Parameter } & \multicolumn{3}{|l|}{ Micelles } \\
\hline & RuMs & OsMs $^{a}$ & P123Ms \\
\hline Aggregation number & $66 \pm 4$ & $52 \pm 6$ & $20 \pm 2$ \\
\hline $\mathrm{Ru} /$ Os complexes per micelle & $59 \pm 14$ & $52 \pm 11$ & 0 \\
\hline DLS diameter $(\mathrm{nm})$ & $11.9 \pm 4.1$ & $11.5 \pm 2.3$ & $19.6 \pm 1.8$ \\
\hline DLS dispersity & 0.04 & 0.03 & 0.03 \\
\hline Cryo-TEM diameter (nm) & $10.45 \pm 3.43$ & $7.85 \pm 1.97$ & $\mathrm{nd}^{b}$ \\
\hline Cryo-TEM dispersity & 1.11 & 1.06 & $\mathrm{nd}^{b}$ \\
\hline SAXS total diameter (nm) & $18.97 \pm 0.54$ & $15.56 \pm 0.27$ & $18.96 \pm 0.23$ \\
\hline SAXS core diameter (nm) & $9.88 \pm 0.25$ & $9.06 \pm 0.12$ & $6.74 \pm 0.06$ \\
\hline SAXS shell diameter (nm) & $9.09 \pm 0.29$ & $6.50 \pm 0.15$ & $12.22 \pm 0.17$ \\
\hline SAXS dispersity & 0.124 & 0.161 & 0.146 \\
\hline
\end{tabular}

RuMs and OsMs micelles determined by DLS and cryo-TEM are in accordance with the core diameter determined by SAXS within experimental error. From these data (scattering length density calculations, degrees of polymerization of Pluronic ${ }^{\circledR} \mathrm{P} 123$, and the molecular formulae of the polymer and of complex 1/2), aggregation numbers for RuMs, OsMs and P123Ms micelles were determined as $20 \pm 2$ monomer chains per P123Ms micelle, $66 \pm 4$ monomer chains per RuMs micelles and $52 \pm 6$ monomer chains per OsMs micelles. Determinations of ruthenium and osmium by inductively coupled plasma mass spectrometry (ICPMS) gave a polymer/complex 1 ratio of $1 / 0.9 \pm 0.11$ for RuMs and 1/1 \pm 0.09 for OsMs showing that the 66 polymer chains self-assembled with $59 \pm 14$ complexes 1 in RuMs and 52 monomer chains self-assembled with $52 \pm 11$ complexes 2 (see Table 1).

\section{Anticancer activity of complexes 1 and 2 and micellar formulations RuMs and OsMs}

Synthetic polymer therapeutics are of particular interest in medicine, due to their synthetic versatility, as well as their tunable properties. ${ }^{24}$ A number of biologically 
active polymer-drug conjugates and polymeric formulations, such as micelles, hydrogels and polymer-coated nanoparticles, are currently in clinical development. ${ }^{25}$ Among the most commonly used polymers for applications in medicine are the ABA Pluronic ${ }^{\circledR}$ triblock block copolymers, which are particularly suitable for the design of bio-inspired, bioengineered and biomimetic polymer nanoparticles. The utilisation of Pluronic ${ }^{\circledR}$ block copolymers as drug delivery systems,${ }^{26-31}$ biological response modifiers, ${ }^{32-36}$ pharmaceutical ingredients, ${ }^{27,37,38}$ and steric stabilizers to lyotropic liquid crystalline particles ${ }^{39-41}$ has led to recent clinical advances. ${ }^{15}$

Inorganic compounds offer different mechanisms of drug action depending on the metal used, their structures and their redox properties..$^{\mathbf{1 1 4 2 - 8 5}}$ They can this be utilized for the design of novel drugs in the treatment of a broad range of diseases, ${ }^{86}$ and their combination with nanotechnology tools, such as polymer nanoparticles, may provide opportunities for tackling medical challenges in the near future. ${ }^{13}$ Surprisingly, only a few studies have been devoted to the encapsulation of inorganic compounds (mainly cisplatin) in Pluronic $\AA$ block copolymer-based nanostructures. ${ }^{\mathbf{8 7 , 8 8}}$

We studied the antiproliferative activity of complexes 1, 2 and micelles RuMs and OsMs in A2780 human ovarian cancer cells (Table 2). Cells were exposed for $24 \mathrm{~h}$ to the complexes (dissolved in 5\% dimethyl sulfoxide (DMSO)/95\% saline and further diluted in cell culture medium until working concentrations in the range of $100-0.01 \mu \mathrm{M}$ were achieved with a maximum DMSO concentration of $1 \%$ ) or micelles $(100 \%$ saline, further diluted with cell culture medium to a range of concentration 200-0.10 $\mu \mathrm{M}$ ). After this, drugs were removed and cells were washed and placed in fresh growth medium for a further $72 \mathrm{~h}$ as a recovery period. Cell viability was then assessed using the sulforhodamine B (SRB) colorimetric assay. Complex 1 is highly potent $\left(\mathrm{IC}_{50} 170 \mathrm{nM}\right)$, about $7 \times$ more potent than the clinical drug cisplatin. Complex $\mathbf{1}$ is also $39 \times$ more potent than RuMs micelles, which still exhibit good (micromolar) activity towards cancer cells and are as potent as the clinical drug carboplatin. Interestingly, RuMs micelles are $4 \times$ more selective than 1, showing only moderate toxicity towards MRC5-fibroblast cells. Finally, the formulation of complexes $\mathbf{1}$ and $\mathbf{2}$ in polymer micelles has allowed dispersal of hydrophobic ruthenium and osmium arene complexes in water in a

Table $2 \quad I_{50}$ values $(\mu \mathrm{M})$ of complexes 1 and 2 and micelles P123Ms, RuMs and OsMs towards A2780 human ovarian cancer cells, $I_{50}$ values $(\mu \mathrm{M})$ of complex 1 and micelles RuMs for MRC5-fibroblast cells, and selectivity factors $\left(\mathrm{IC}_{50}\left(\mathrm{MRC}_{5}\right) / \mathrm{IC}_{50}(\mathrm{~A} 2780)\right)$

\begin{tabular}{llll}
\hline & $\mathrm{IC}_{50}(\mu \mathrm{M})$ & & \\
\cline { 2 - 4 } Compound & $\mathrm{A} 2780$ & MRC5-fibroblast & Selectivity factor \\
\hline P123Ms & $>100$ & nd & - \\
$\mathbf{1}$ & $0.17 \pm 0.02$ & $0.31 \pm 0.03$ & 1.82 \\
$\mathbf{2}$ & $2.50 \pm 0.09$ & nd & - \\
RuMs & $6.69 \pm 0.33$ & $51.6 \pm 0.9$ & 7.71 \\
OsMs & $117.50 \pm 0.18$ & nd & - \\
Cisplatin & $1.20 \pm 0.10$ & 9.5 (ref. 89) & - \\
Carboplatin & $6.0 \pm 0.7$ (ref. 90) & nd & -
\end{tabular}


manner suitable for administration to cancer cells (administration to cancer cells in water, without the need to add DMSO).

\section{Conclusion}

We have encapsulated highly hydrophobic carborane-containing precious metal complexes in triblock copolymer micelles. This has allowed dispersal of hydrophobic ruthenium and osmium arene complexes in water in a manner suitable for administration to cancer cells. Although entrapment of the 16-electron complexes 1 and 2 in Pluronic ${ }^{\circledR}$ micelles leads to a reduction in their anticancer potency, the micelles exhibit enhanced selectivity towards cancer cells compared to normal cells. Polymer encapsulation of metal carborane complexes also provides the potential for delivering high amounts of boron to cells, which is of interest for boron neutron capture therapy (BNCT). The neutron capture ability of such micelles is currently under investigation.

\section{Experimental section}

\section{Materials}

The preparation of the complexes $[\mathrm{Ru} / \mathrm{Os}(p$-cym)(1,2-dicarba-closo-dodecaborane1,2-dithiolato)] (1 and 2) was based on a previous report. ${ }^{17}$ The preparation of the OsMs micelles was based on a previous report. ${ }^{19}$ The triblock copolymer P123 [poly(ethylene glycol)-block-poly(propylene glycol)-block-poly(ethylene glycol)] was purchased from Sigma-Aldrich and used as received. Anhydrous tetrahydrofuran (Aldrich) was used. 18.2 mega-ohm purity water was collected from a Purelab® UHQ USF Elga system. Holey carbon grids with 200 mesh and lacey carbon grids were purchased from Quantifoil Micro Tools Gmbh and Elektron Technology UK Ltd, respectively, and used as received.

\section{Synthesis of RuMs}

A tetrahydrofuran (THF) solution $(1 \mathrm{~mL})$ of complex $1\left(5 \mathrm{mg} \mathrm{mL}{ }^{-1}\right)$ was added to an aqueous solution $(10 \mathrm{~mL})$ of polymer P123 $\left(5 \mathrm{mg} \mathrm{mL}^{-1}\right)$ and the resultant mixture was stirred at ambient temperature for $4 \mathrm{~h}$. The solution was then dialyzed to remove the THF (MWCO = $1000 \mathrm{Da})$, for $48 \mathrm{~h}$, and then freeze-dried to give RuMs. A similar procedure was used for synthesizing OsMs with 1 mol equiv. of the Os analogue and $1 \mathrm{~mol}$ equiv. of polymer P123.

\section{Instrumentation}

UV-visible spectroscopy. UV-visible absorption spectra were recorded on a temperature-controlled Varian CARY 300 Biospectrophotometer using $1 \mathrm{~cm}$ pathlength quartz cuvettes $(0.5 \mathrm{~mL})$.

Inductively coupled plasma mass spectrometry (ICP-MS). Osmium or ruthenium content was determined using an ICP-MS Agilent technologies 7500 series instrument. The standard for osmium was purchased from Aldrich. Calibration curves were prepared using Ru/Os standard solutions in double deionised water (ddw) with $3 \%$ nitric acid, ranging between 50 and 0.5 ppb (9 points). Samples were freshly prepared in ddw with $3 \%$ nitric acid. Readings were made in no-gas mode with a detection limit of 1 ppt. 
Dynamic light scattering (DLS). The hydrodynamic diameter $\left(D_{\mathrm{h}}\right)$ of nanoparticles was determined by DLS. Typically, an aqueous nanoparticle solution was measured with a Malvern Zetasizer NanoS instrument equipped with a $4 \mathrm{~mW} \mathrm{He}-$ $\mathrm{Ne} 633 \mathrm{~nm}$ laser module at $25{ }^{\circ} \mathrm{C}$. Measurements were carried out at a detector angle of $173^{\circ}$ (back scattering). Data were analyzed by the Malvern DTS 6.20 software. $D_{\mathrm{h}}$ was calculated by fitting the apparent diffusion coefficient in the Stokes-Einstein equation $D_{\mathrm{h}}=k T /\left(3 \pi \eta D_{\text {app }}\right)$, where $k$ is the Boltzmann constant, $T$ is the temperature and $\eta$ is the viscosity of the solvent. $D_{\mathrm{h}}$ coincides with the hydrodynamic diameter when the sample is made of monodispersed spherical particles $\left(D_{\text {app }}\right.$ equals the translational diffusion $\left.D_{\mathrm{t}}\right)$.

Cryogenic electron microscopy (cryo-TEM). A JEOL 2010F TEM was operated at $200 \mathrm{keV}$ and images were recorded on a Gatan UltraScan 4000 camera for cryoTEM and glow discharge. The samples were prepared at ambient temperature by placing a droplet on a TEM grid. The extra liquid was then blotted with a filter paper and the grid was inserted into liquid ethane at its freezing point. The frozen samples were subsequently kept under liquid nitrogen.

Small-angle X-ray scattering (SAXS). Measurements were carried out on the SAXS beamline at the Australian Synchrotron facility at a photon energy of $11 \mathrm{keV}$. The samples in solution were in $1.5 \mathrm{~mm}$ diameter quartz capillaries. The measurements were collected at a sample to detector distance of $3.252 \mathrm{~m}$ to give a $q$ range of 0.004 to $0.2 \AA^{-1}$, where $q$ is the scattering vector and is related to the scattering angle $(\theta)$ and the photon wavelength $(\lambda)$ by the following eqn (1):

$$
q=\frac{4 \pi \sin (\theta)}{\lambda}
$$

The scattering from a blank $\left(\mathrm{H}_{2} \mathrm{O}\right)$ was measured in the same location as sample collection and was subtracted for each measurement. Data were normalized for total transmitted flux using a quantitative beamstop detector and absolute scaled using water as an absolute intensity standard. The two-dimensional SAXS images were converted in one-dimensional SAXS profiles $(I(q)$ versus $q$ ) by circular averaging, where $I(q)$ is the scattering intensity. Functions were used from the NCNR package. Scattering length densities were calculated using the "Scattering Length Density Calculator" provided by NIST Center for Neutron Research.

Cell culture. A2780 human ovarian carcinoma and MRC5 human fetal lung fibroblasts were obtained from the European Collection of Cell Cultures (ECACC). Both cell lines were grown in Roswell Park Memorial Institute medium (RPMI1640) supplemented with $10 \%$ of fetal calf serum, $1 \%$ of $2 \mathrm{mM}$ glutamine and $1 \%$ penicillin/streptomycin. All cells were grown as adherent monolayers at $310 \mathrm{~K}$ in a $5 \% \quad \mathrm{CO}_{2}$ humidified atmosphere and passaged at approximately $70-80 \%$ confluency.

In vitro growth inhibition assay. Briefly, 96-well plates were used to seed 5000 cells per well. The plates were left to pre-incubate in drug-free media at $310 \mathrm{~K}$ for $48 \mathrm{~h}$ before adding different concentrations of the compounds to be tested. A drug exposure period of $24 \mathrm{~h}$ was allowed. After this, supernatants were removed by suction and each well was washed with PBS. A further $48 \mathrm{~h}$ was allowed for the cells to recover in drug-free medium at $310 \mathrm{~K}$. The SRB assay was used to determine cell viability. $\mathrm{IC}_{50}$ values, as the concentration which caused $50 \%$ of cell 
death, were determined as duplicates of triplicates in two independent sets of experiments and their standard deviations were calculated.

\section{Acknowledgements}

We thank the Leverhulme Trust (Early Career Fellowship no. ECF-2013-414 to NPEB), the University of Warwick (Grant no. RDF 2013-14 to NPEB), the Swiss National Science Foundation (Grant no. PA00P2_145308 to NPEB and PBNEP2_142949 to APB), the ERC (Grant no. 247450 to PJS), EPSRC (EP/G004897/ 1 to APB, and EP/F034210/1 to PJS), Institute of Advanced Study (IAS) - University of Warwick (Fellowship to JJSB), and Science City (AWM/ERDF) for support. We thank the Wellcome Trust (055663/Z/98/Z) for funding to the Electron Microscopy Facility, School of Life Sciences, University of Warwick. We also thank COST Action CM1105 for stimulating discussions, Thomas Wilks for supplying the micelle image for Fig. 1, Dr Magdalena Moss for technical asssistance with the cell culture, the Australian Synchrotron and the University of Monash for allocation of beamtime on the SAXS/WAXS beamline and funding.

\section{Notes and references}

1 Z. J. Lesnikowski, Collect. Czech. Chem. Commun., 2007, 72, 1646-1658.

2 R. Djeda, J. Ruiz, D. Astruc, R. Satapathy, B. P. Dash and N. S. Hosmane, Inorg. Chem., 2010, 49, 10702-10709.

3 K. Kokado, M. Tominaga and Y. Chujo, Macromol. Rapid Commun., 2010, 31, 1389-1394.

4 D. C. Kennedy, D. R. Duguay, L.-L. Tay, D. S. Richeson and J. P. Pezacki, Chem. Commun., 2009, 6750-6752.

5 J. F. Valliant, K. J. Guenther, A. S. King, P. Morel, P. Schaffer, O. O. Sogbein and K. A. Stephenson, Coord. Chem. Rev., 2002, 232, 173-230.

6 W. Tjarks, R. Tiwari, Y. Byun, S. Narayanasamy and R. F. Barth, Chem. Commun., 2007, 4978-4991.

7 I. B. Sivaev and V. V. Bregadze, Eur. J. Inorg. Chem., 2009, 2009, 1433-1450.

8 M. Scholz and E. Hey-Hawkins, Chem. Rev., 2011, 111, 7035-7062.

9 S. Korbe, P. J. Schreiber and J. Michl, Chem. Rev., 2006, 106, 5208-5249.

10 G. Süss-Fink, Dalton Trans., 2010, 39, 1673-1688.

11 A. M. Pizarro, N. P. E. Barry and P. J. Sadler, in Comprehensive Inorganic Chemistry II, ed. J. Reedijk, Elsevier, 2013, vol. 3, pp. 752-784.

12 N. P. E. Barry and P. J. Sadler, Chem. Soc. Rev., 2012, 41, 3264-3279.

13 N. P. E. Barry and P. J. Sadler, ACS Nano, 2013, 7, 5654-5659.

14 http://worldaccount.basf.com/wa/NAFTA/Catalog/ChemicalsNAFTA/pi/BASF/ Brand/pluronic.

15 A. Pitto-Barry and N. P. E. Barry, Polym. Chem., 2014, 5, 3291-3297.

16 M. A. Soriano-Ursúa, B. C. Das and J. G. Trujillo-Ferrara, Expert Opin. Ther. Pat., 2014, 24, 485-500.

17 M. Herberhold, H. Yan and W. Milius, J. Organomet. Chem., 2000, 598, 142149.

18 N. P. E. Barry, T. F. Kemp, P. J. Sadler and J. V. Hanna, Dalton Trans., 2014, 43, 4945-4949. 
19 N. P. E. Barry, A. Pitto-Barry, A. M. Sanchez, A. P. Dove, R. J. Procter, J. J. Soldevila-Barreda, N. Kirby, I. Hands-Portman, C. J. Smith, R. K. O’Reilly, R. Beanland and P. J. Sadler, Nat. Commun., 2014, 5, 3851.

20 A. Parmar, V. K. Aswal and P. Bahadur, Spectrochim. Acta, Part A, 2012, 97, 137143.

21 S. Kline, J. Appl. Crystallogr., 2006, 39, 895-900.

22 A. Guinier and G. Fournet, Small-angle scattering of X-rays, Wiley, New York, 1955.

23 J. B. Hayter, in Physics of Amphiphiles-Micelles, Vesicles, and Microemulsions, ed. V. DeGiorgio and M. Corti, North-Holland Publishing Company, 1983, pp. 5993.

24 A. R. Kirtane and J. Panyam, Nat. Nanotechnol., 2013, 8, 805-806.

25 O. C. Steinbach, Ther. Delivery, 2014, 5, 113-118.

26 D. Y. Alakhova, Y. Zhao, S. Li and A. V. Kabanov, PLoS One, 2013, 8, e72238.

27 E. V. Batrakova, S. Li, A. M. Brynskikh, A. K. Sharma, Y. Li, M. Boska, N. Gong, R. L. Mosley, V. Y. Alakhov, H. E. Gendelman and A. V. Kabanov, J. Controlled Release, 2010, 143, 290-301.

28 E. V. Batrakova and A. V. Kabanov, J. Controlled Release, 2008, 130, 98-106.

29 T. Minko, E. V. Batrakova, S. Li, Y. Li, R. I. Pakunlu, V. Y. Alakhov and A. V. Kabanov, J. Controlled Release, 2005, 105, 269-278.

30 A. V. Kabanov, E. V. Batrakova and V. Y. Alakhov, J. Controlled Release, 2002, 82, 189-212.

31 E. V. Batrakova, S. Li, W. F. Elmquist, D. W. Miller, V. Y. Alakhov and A. V. Kabanov, Br. J. Cancer, 2001, 85, 1987-1997.

32 D. Y. Alakhova, N. Y. Rapoport, E. V. Batrakova, A. A. Timoshin, S. Li, D. Nicholls, V. Y. Alakhov and A. V. Kabanov, J. Controlled Release, 2010, 142, 89-100.

33 E. V. Batrakova, S. Li, V. Y. Alakhov, W. F. Elmquist, D. W. Miller and A. V. Kabanov, Pharm. Res., 2003, 20, 1581-1590.

34 E. Batrakova, S. Li, V. Alakhov, D. Miller and A. Kabanov, J. Pharmacol. Exp. Ther., 2003, 304, 845-854.

35 A. Kabanov, E. Batrakova and V. Alakhov, Adv. Drug Delivery Rev., 2002, 54, 759779.

36 A. Venne, S. Li, R. Mandeville, A. Kabanov and V. Alakhov, Cancer Res., 1996, 56, 3626-3629.

37 E. R. Gariepy and J. C. Leroux, Eur. J. Pharm. Biopharm., 2004, 58, 409-426.

38 I. R. Schmolka, Poloxamers in the Pharmaceutical Industry, CRC Press, Boca Ratin FL, 1991.

39 J. Y. T. Chong, X. Mulet, L. J. Waddington, B. J. Boyd and C. J. Drummond, Soft Matter, 2011, 7, 4768-4777.

40 K. W. Lee, T. H. Nguyen, T. Hanley and B. J. Boyd, Int. J. Pharm., 2009, 365, 190199.

41 B. J. Boyd, Y. D. Dong and T. Rades, J. Liposome Res., 2009, 19, 12-28.

42 Z. Liu and P. J. Sadler, Acc. Chem. Res., 2014, 47, 1174-1185.

43 Y. Zhao, J. A. Woods, N. J. Farrer, K. S. Robinson, J. Pracharova, J. Kasparkova, O. Novakova, H. Li, L. Salassa, A. M. Pizarro, G. J. Clarkson, L. Song, V. Brabec and P. J. Sadler, Chem.-Eur. J., 2013, 19, 9578-9591.

44 N. A. Smith and P. J. Sadler, Philos. Trans. R. Soc., A, 2013, 371, 1995. 
45 I. Romero-Canelón, L. Salassa and P. J. Sadler, J. Med. Chem., 2013, 56, 12911300.

46 I. Romero-Canelón and P. J. Sadler, Inorg. Chem., 2013.

47 Z. Liu, I. Romero-Canelón, B. Qamar, J. M. Hearn, A. Habtemariam, N. P. E. Barry, A. M. Pizarro, G. J. Clarkson and P. J. Sadler, Angew. Chem., Int. Ed., 2014, 53, 3941-3946.

48 Y. Fu, R. Soni, M. J. Romero, A. M. Pizarro, L. Salassa, G. J. Clarkson, J. M. Hearn, A. Habtemariam, M. Wills and P. J. Sadler, Chem.-Eur. J., 2013, 19, 15199-15209.

49 J. Schulz, J. Tauchman, I. Císařová, T. Riedel, P. J. Dyson and P. Štěpnička, J. Organomet. Chem., 2014, 751, 604-609.

50 A. A. Nazarov, C. G. Hartinger and P. J. Dyson, J. Organomet. Chem., 2014, 751, 251-260.

51 K. J. Kilpin, S. Crot, T. Riedel, J. A. Kitchen and P. J. Dyson, Dalton Trans., 2014, 43, 1443-1448.

52 C. M. Clavel, E. Paunescu, P. Nowak-Sliwinska and P. J. Dyson, Chem. Sci., 2014, 5, 1097-1101.

53 K. J. Kilpin and P. J. Dyson, Chem. Sci., 2013, 4, 1410-1419.

54 G. Gupta, A. Garci, B. S. Murray, P. J. Dyson, G. Fabre, P. Trouillas, F. Giannini, J. Furrer, G. Suss-Fink and B. Therrien, Dalton Trans., 2013, 42, 15457-15463.

55 F. Giannini, J. Furrer, G. Süss-Fink, C. M. Clavel and P. J. Dyson, J. Organomet. Chem., 2013, 744, 41-48.

56 A. Leonidova, V. Pierroz, R. Rubbiani, J. Heier, S. Ferrari and G. Gasser, Dalton Trans., 2014, 43, 4287-4294.

57 T. Joshi, V. Pierroz, C. Mari, L. Gemperle, S. Ferrari and G. Gasser, Angew. Chem., Int. Ed., 2014, 53, 2960-2963.

58 M. Patra, T. Joshi, V. Pierroz, K. Ingram, M. Kaiser, S. Ferrari, B. Spingler, J. Keiser and G. Gasser, Chem.-Eur. J., 2013, 19, 14768-14772.

59 M. Patra, K. Ingram, A. Leonidova, V. Pierroz, S. Ferrari, M. N. Robertson, M. H. Todd, J. Keiser and G. Gasser, J. Med. Chem., 2013, 56, 9192-9198.

60 M. Patra, J. Hess, S. Konatschnig, B. Spingler and G. Gasser, Organometallics, 2013, 32, 6098-6105.

61 P. K. Sasmal, C. N. Streu and E. Meggers, Chem. Commun., 2013, 49, 1581-1587.

62 Y. Xiang, C. Fu, T. Breiding, P. K. Sasmal, H. Liu, Q. Shen, K. Harms, L. Zhang and E. Meggers, Chem. Commun., 2012, 48, 7131-7133.

63 A. L. Merkel, E. Meggers and M. Ocker, Expert Opin. Ther. Pat., 2012, 21, 425436.

64 A. Kastl, A. Wilbuer, A. L. Merkel, L. Feng, P. Di Fazio, M. Ocker and E. Meggers, Chem. Commun., 2012, 48, 1863-1865.

65 E. Meggers, Angew. Chem., Int. Ed., 2011, 50, 2442-2448.

66 K. D. Mjos and C. Orvig, Chem. Rev., 2014, 114, 4540-4563.

67 M. A. Telpoukhovskaia and C. Orvig, Chem. Soc. Rev., 2013, 42, 1836-1846.

68 Y. L. K. Tan, P. Pigeon, S. Top, E. Labbe, O. Buriez, E. A. Hillard, A. Vessieres, C. Amatore, W. K. Leong and G. Jaouen, Dalton Trans., 2012, 41, 7537-7549.

69 G. Sava, G. Jaouen, E. A. Hillard and A. Bergamo, Dalton Trans., 2012, 41, 82268234.

70 A. Vessières, C. Corbet, J. M. Heldt, N. Lories, N. Jouy, I. Laïos, G. Leclercq, G. Jaouen and R.-A. Toillon, J. Inorg. Biochem., 2010, 104, 503-511. 
71 J. W. Yi, N. P. E. Barry, M. A. Furrer, O. Zava, P. J. Dyson, B. Therrien and B. H. Kim, Bioconjugate Chem., 2012, 23, 461-471.

72 A. Pitto-Barry, O. Zava, P. J. Dyson, R. Deschenaux and B. Therrien, Inorg. Chem., 2012, 51, 7119-7124.

73 N. P. E. Barry, O. Zava, W. Wu, J. Zhao and B. Therrien, Inorg. Chem. Commun., 2012, 18, 25-28.

74 N. P. E. Barry, O. Zava, P. J. Dyson and B. Therrien, J. Organomet. Chem., 2012, 705, 1-6.

75 G. S. Smith and B. Therrien, Dalton Trans., 2011, 40, 10793-10800.

76 A. Pitto-Barry, N. P. E. Barry, O. Zava, R. Deschenaux and B. Therrien, Chem.Asian J., 2011, 6, 1595-1603.

77 A. Pitto-Barry, N. P. E. Barry, O. Zava, R. Deschenaux, P. J. Dyson and B. Therrien, Chem.-Eur. J., 2011, 17, 1966-1971.

78 L. E. H. Paul, B. Therrien and J. Furrer, Inorg. Chem., 2011, 51, 1057-1067.

79 N. P. E. Barry, O. Zava, J. Furrer, P. J. Dyson and B. Therrien, Dalton Trans., 2010, 39, 5272-5277.

80 N. P. E. Barry, O. Zava, P. J. Dyson and B. Therrien, Aust. J. Chem., 2010, 63, 1529-1537.

81 N. P. E. Barry, F. Edafe, P. J. Dyson and B. Therrien, Dalton Trans., 2010, 39, 2816-2820.

82 G. Gupta, J. Mahesh Kumar, A. Garci, N. Rangaraj, N. Nagesh and B. Therrien, ChemPlusChem, 2014, 79, 610-618.

83 M. Pernot, N. P. E. Barry, T. Bastogne, C. Frochot, M. Barberi-Heyob and B. Therrien, Inorg. Chim. Acta, 2014, 414, 134-140.

84 G. Gupta, B. Murray, P. Dyson and B. Therrien, Materials, 2013, 6, 5352-5366. 85 P. Chellan, K. M. Land, A. Shokar, A. Au, S. H. An, D. Taylor, P. J. Smith, T. Riedel, P. J. Dyson, K. Chibale and G. S. Smith, Dalton Trans., 2014, 43, 513-526.

86 N. P. E. Barry and P. J. Sadler, Chem. Commun., 2013, 49, 5106-5131.

87 A. Sonoda, N. Nitta, S. Ohta, A. Nitta-Seko, S. Morikawa, Y. Tabata, M. Takahashi and K. Murata, CardioVasc. Interventional Radiol., 2010, 33, 135-142.

88 J.-Y. Fang, S.-H. Hsu, Y.-L. Leu and J.-W. Hu, J. Biomater. Sci., Polym. Ed., 2009, 20, 1031-1047.

89 S. Dhar and S. J. Lippard, Proc. Natl. Acad. Sci. U. S. A., 2009, 106, 22199-22204.

90 R. E. Aird, J. Cummings, A. A. Ritchie, M. Muir, R. E. Morris, H. Chen, P. J. Sadler and D. I. Jodrell, Br. J. Cancer, 2002, 86, 1652-1657. 